\title{
A singularidade das práticas culturais
}

\author{
Entrevista com Bernard Lahire
}

\section{Realizada por Enio Passiani ${ }^{a}$, Julio Souto Salom e Gabriele dos Anjos ${ }^{c}$}

Professor da École Normale Supérieure de Lyon; diretor do grupo de pesquisa Dispositions, pouvoirs, culture et socialisations do Centre Max Weber; laureado, em 2012, com a Médaille d'Argent, prêmio do Centre National de la Recherche Scientifique (CNRS) concedido todo ano a pesquisadores reconhecidos pela originalidade e importância de seus trabalhos, tanto no âmbito francês quanto internacionalmente; felizmente, presença frequente no mundo acadêmico brasileiro, Bernard Lahire é, hoje, sem a menor sombra de dúvida, uma referência incontornável da sociologia contemporânea.

Sua sociologia das práticas culturais ${ }^{1}$ apoia-se em pesquisas empíricas de um leque variado de objetos de investigação, como hábitos de leitura, práticas de escrita, consumos culturais e a articulação entre as condições sociais dos escritores e os processos de criação literária, todos emoldurados e balizados por uma mesma preocupação teórica, a saber, a singularidade dos agentes sociais. Daí a preocupação em elaborar e desenvolver uma sociologia em escala individual cujos resultados lhe permitiram propor uma teoria da ação que dialoga frontal e criticamente com a obra de Pierre Bourdieu, assumido pelo próprio Lahire como seu principal, mas não único, interlocutor intelectual. ${ }^{2}$

A oposição de Lahire a Bourdieu, no entanto, não significa o completo abandono do segundo pelo primeiro; ao contrário, é como se a sociologia de Lahire completasse, atualizasse e mesmo refinasse, em suas lacunas e pontos cegos, a de Bourdieu, fazendo avançar, dessa maneira, o conhecimento sociológico a propósito de uma questão nuclear, e até hoje de difícil resposta para as ciências sociais, que é

a Professor do Departamento e do Programa de Pós-Graduação em Sociologia da Universidade Federal do Rio Grande do Sul (UFRGS). E-mail: eniopassiani@gmail.com.

b Doutorando em Sociologia no Programa de Pós-Graduação em Sociologia da UFRGS e professor substituto no Departamento de Sociologia na mesma universidade.

E-mail: juliosouto2103@gmail.com.

c Pesquisadora da Fundação de Economia e Estatística (FEE-RS).

E-mail: gabrieleanjos@gmail.com.

1 A nosso ver, definir o projeto intelectual de Lahire como uma "sociologia das práticas culturais" nos parece mais preciso do que referenciá-la genericamente como "sociologia da cultura", até porque nos parece também mais fiel aos temas, questões e problemas empíricos investigados pelo autor.

2 Tal confissão se encontra, entre outros lugares, na entrevista concedida por Lahire à revista Sociologias em seu número 28. Ao final desta apresentação o leitor encontrará a referência bibliográfica completa. 
a relação entre indivíduo e sociedade, ou, se preferirmos, entre agente estrutura, ou ainda entre subjetivismo e objetivismo. Não importa muito qual nomenclatura se adote, a preocupação é a mesma: descobrir até que ponto as estruturas se impõem e determinam os indivíduos, qual o grau e alcance da autonomia do agente e sua capacidade de improvisar diante dos constrangimentos sociais.

Sem aderir ao individualismo metodológico ou às perspectivas pós-modernas que encaram a fragmentação do agente como pressuposto a priori ao invés de tomá-la como hipótese de trabalho, a proposta de Lahire sugere que se pode compreender de modo mais profundo e adequado certos fenômenos macrossociológicos observando de perto o comportamento individual. Para ele, a ação pode oscilar entre a reflexividade - que equivale a momentos de preparação e planejamento - e momentos de performance, de urgência prática sem qualquer forma de racionalização imediata. Frequentemente, os agentes mobilizam em suas ações um estoque plural e até contraditório de disposições adquiridas e internalizadas em múltiplos processos de socialização que ocorrem em contextos sociais heterogêneos. Observa-se justamente nesse ponto sua divergência em relação a Bourdieu, para quem, segundo Lahire, há um único princípio gerador de todas as práticas, o habitus, que pode ser transferido de um domínio a outro, resultando, portanto, numa reprodução estável do status quo. Para Lahire, o "habitus monolítico" proposto por Bourdieu não é falso, mas equivale apenas a um caso singular do possível (social) que não pode ser generalizado a todas as populações e situações. ${ }^{3}$

Essas e outras questões são tratadas na entrevista que se segue. Gostaríamos, para arrematar, de agradecer imensamente ao Professor Bernard Lahire por toda sua gentileza e solicitude, e também aos esforços e generosidade da Professora Cinara L. Rosenfield, responsável pela visita do Professor Lahire ao Departamento e ao Programa de Pós-Graduação em Sociologia da Universidade Federal do Rio Grande do Sul em 2014, que em meio a uma agenda tão ocupada conseguiu mesmo assim conceder-nos esta oportunidade.

Revista Plural Professor Lahire, queremos primeiramente lhe agradecer por esta ocasião. A primeira questão pode ser vista como uma pequena provocação: no livro Coisas ditas, ${ }^{4}$ Bourdieu afirma que, de um ponto de vista científico, é mais

3 A sociologia de Lahire, assim como qualquer outra, também é alvo de muitas críticas, acusando-a, inclusive, de recair num determinismo objetivista semelhante ao de Bourdieu. A esse respeito, consultar: Alves (2016), Nogueira (2016) e Vandenberghe (2016).

4 Bourdieu, Pierre. Choses dites. Paris: Minuit, 1987. (Collection Le sens commun). Edição brasileira: Coisas ditas. São Paulo: Brasiliense, 2004, p. 65-66. 
interessante utilizar Marx contra Marx, Durkheim e Weber contra Marx, Marx e Weber contra Durkheim e assim sucessivamente. Em sua prática sociológica, você utiliza Bourdieu contra Bourdieu? E sua sociologia é uma denegação ou uma atualização da sociologia de Pierre Bourdieu?

Bernard Lahire É uma questão muito provocante! Para mim, é o que chamo de um "prolongamento crítico", que pode ser visto nessa pequena fórmula que por vezes utilizo: "trabalhar com Bourdieu contra Bourdieu”. É um pouco redutor dizer isso, pois eu penso em ler Bourdieu também com outros autores, evidentemente. Primeiramente, há autores para mim importantes - são muitos para serem nominados -, mas eu penso em Foucault, por exemplo; eu penso em autores não tão utilizados na sociologia e que foram muito importantes na minha formação, como, por exemplo, Mikhail Bakhtin, que é mais estudado em história ou em teoria literária que em sociologia; eu penso também em filósofos como Maurice Merleau-Ponty, etc. Então, para mim, é um prolongamento, e de forma alguma uma negação completa da obra de Bourdieu. Na França, há colegas que dizem: "ele se opõe a Bourdieu, fazendo outra coisa paralelamente, sem dialogar, por vezes criticando de uma maneira muito sumária, rápida, Bourdieu”. No entanto, todas as minhas críticas encontram apoio no interior da tradição que Bourdieu representa. Bourdieu dedicou seu tempo a lembrar que ele foi um descendente de Durkheim, de Weber e de Marx, de uma certa maneira... É uma sociologia que ao mesmo tempo leva em conta a formação dos indivíduos e o que se chama de "disposições sociais", um conceito na minha opinião muito importante, e ainda mais importante que o conceito de habitus. Ele é muito sensível às relações de dominação no mundo social, uma coisa que ele retoma tanto de Max Weber como de Marx, por exemplo. E mais, ele é alguém que acredita que se pode atingir uma ciência social um pouco objetiva, ao se trabalhar com método, sendo reflexivo sobre a maneira como se trabalha, sobre os dados que se produz, etc. Tudo isso, eu penso, me parece ser evidência de meu ofício de sociólogo. Então, eu me sinto totalmente inserido nessa tradição, uma tradição, para dizer outra vez, que vem de Durkheim, de Weber, de Marx, e que foi continuada por antropólogos e sociólogos como Maurice Halbwachs, Marcel Mauss e também continuada por Bourdieu, por Jean-Claude Passeron e outros.

Revista Plural Há aqui no Brasil um tipo de preconceito contra a sociologia da literatura e do campo intelectual. Essa sociologia não foi considerada por certo tempo uma sociologia relevante. Por oposição, pensamos na sociologia francesa, que estabeleceu uma tradição importante de pesquisa sociológica da literatura. 
Talvez você não conheça a sociologia brasileira em todas as suas particularidades, mas você pode formular uma hipótese para explicar esse tipo de fenômeno? Bernard Lahire É difícil, pois mesmo na França a sociologia da literatura não é uma sociologia muito reconhecida. Há os grandes nomes, como Bourdieu, com seu livro As regras da arte,$^{5}$ seu trabalho sobre Flaubert, ou Lucien Goldmann, que hoje em dia não é mais lido pelos sociólogos - é preciso também levar isso em conta. Eu penso na seguinte hipótese, ligando coisas totalmente concretas na história das instituições e na história de indivíduos que fazem pesquisa: na França, se essa sociologia tem um pouco mais de peso, é porque alguém como Bourdieu, um nome muito legítimo, decidiu trabalhar sobre a literatura, sobre o campo literário, sobre Flaubert, Baudelaire, enfim, sobre o campo literário no fim do século XIX. É porque Bourdieu começou a trabalhar sobre essas questões que elas ganharam um pouco mais de peso. Mas se você considera os pais fundadores, nenhum trabalhou sobre a literatura. Durkheim não fala de literatura, Max Weber não faz estudos sobre literatura (mas ele faz estudos sobre a música, não é desinteressante...), Marx não fala disso como sociólogo, na verdade. Depois, Halbwachs, todos da escola de Durkheim, pesquisam o trabalho, a religião, a educação, muito pouco a cultura (os grandes domínios da cultura) e, enfim, a literatura estava completamente ausente. Toda essa pesquisa é uma coisa muito recente e eu acho que ela se coloca um pouco "por acaso". É porque Bourdieu decidiu tomar por objeto um autor como Flaubert. Em seu caso, se ele fez isso, é porque há um precedente também, que é o Flaubert de Sartre. Então, vejam, no caso francês, que eu conheço um pouco melhor, a pesquisa sobre o assunto está ligada a cadeias de transmissão como essa. Bourdieu foi ao mesmo tempo admirador de Sartre e muito irritado com Sartre. Admirador da capacidade de Sartre de fazer as coisas em todos os domínios: teatro, escrita literária romanesca, filosofia, engajamento político, etc. E ao mesmo tempo muito agressivo contra Sartre, pois evidentemente Sartre tem um lado muito antissociólogo, no plano de análise que desenvolve. Então, no momento em que Bourdieu publica seu trabalho sobre Flaubert, ele o faz contra Sartre. E, por outro lado, Sartre morrera muito tempo antes. Sartre morrera em 1980 e As regras da arte foi publicado em 1992; doze anos após, Bourdieu está ainda em diálogo com Sartre. E, além disso, na França, havia uma certa publicidade do livro que dizia "o Flaubert de Bourdieu” (está subentendido “após o Flaubert de Sartre”). Então, por tudo isso, é normal que haja

5 Bourdieu, Pierre. Les Règles de l'art: Genèse et structure du champ littéraire. Paris: Seuil, 1998. Edição brasileira: As regras da arte: gênese e estrutura do campo literário. São Paulo: Companhia das Letras, 1996. 
esse interesse da sociologia pela literatura com esses dois autores. Mas, no Brasil, eu não sei. Talvez em São Paulo...

Revista Plural Como você considera a literatura enquanto objeto sociológico em relação à história da sociologia?

Bernard Lahire A priori, a literatura é um objeto nobre. Então, o problema que pesa sobre a literatura não é o mesmo que pesa sobre o esporte, por exemplo. Quando Norbert Elias começou a trabalhar sobre o esporte, ele era um filósofo, e para a filosofia isso significa uma decadência, um declínio. Aí se vê bem que há uma hierarquia de objetos, e o esporte não ocupava, à época de Elias, uma posição muito alta na hierarquia dos objetos. Hoje em dia eu não sei se é a mesma coisa... Também no Brasil é muito diferente... Mas o futebol continua a ser algo muito popular na França e não muito considerado na hierarquia dos objetos culturais. Quando se faz sociologia do esporte, frequentemente se tem dificuldade de fazer reconhecer o interesse de seu trabalho. Isso porque o objeto é muito baixo e a literatura é muito alta em um país como a França. Mesmo no Brasil, é ensinada pelo sistema escolar, é aceita, respeitada, e ainda que poucas pessoas leiam, mesmo assim há autores muito conhecidos. Então, quem vai se ocupar de qual objeto em tal momento de seu percurso como sociólogo, é algo frequentemente ligado a histórias muito biográficas. ${ }^{6}$ Talvez possamos esperar que haja uma forte sociologia da literatura na França.

Revista Plural Você pensa que a literatura é uma espécie de sociologia do conhecimento?

Bernard Lahire Sua questão supõe que a literatura seja uma forma de conhecimento. Sim, podemos dizer isso, mas ao mesmo tempo reduziríamos em parte o que é a literatura. Não podemos negar a especificidade da literatura. Porque se dizemos que a literatura é uma forma de conhecimento, é necessário explicar, por exemplo, se pesquisamos as visões de mundo, as estruturas cognitivas, os autores que escrevem romances, peças de teatro, poesia, etc., e reduzimos a função da literatura porque há uma dimensão estética, formal, estilística.

Então, eu creio que a sociologia da literatura pode partir da sociologia do conhecimento, isso é certo. Mais ainda, com a estrutura romanesca, notadamente... De fato, eu estou convencido disso, mas também há muitos colegas que

6 Algo como biografias individuais inseridas em uma história disciplinar nacional [Nota dos entrevistadores]. 
trabalharam a partir dessa ideia. Por exemplo, Jacques Dubois, da Universidade de Liège (Bélgica), trabalhou sobre os romancistas "do real", observando que os escritores de romance franceses do século XIX, desde Balzac, Stendhal, Flaubert, Zola, Céline, Proust, etc., são pessoas que quiseram fazer "sociologia antes da sociologia”. Quer dizer, eles quiseram mostrar como o mundo social funcionava, eles quiseram desvelar a violência do mundo, as relações de dominação, as estratégias das pessoas... Balzac fez isso: mostrar as estratégias das pessoas que querem progredir na sociedade, e eles aprendem a fazer bons casamentos, a utilizar técnicas para conseguir obter poder, etc. Em Proust, há uma análise formidável da maneira pela qual as pessoas que possuem heranças sociais contrastantes agem em interações diferentes, em meios diferentes... É um interacionismo estrutural, se é possível dizer isso.

\section{Revista Plural Há uma literatura quase científica no século XIX?}

Bernard Lahire Sim... Primeiro, Zola disse que ele quer fazer algo de científico. Ele falava do naturalismo como um romance experimental, à imagem da medicina experimental, de Claude Bernard. Eu acho que ele levou um pouco longe as coisas, mas ele teve essa vontade. Foram publicados os cadernos etnográficos de Zola. Sabe-se também que Flaubert escrevia notas, ele fez croquis para depois os descrever. Ele não escreve sobre os cirurgiões sem ler livros de cirurgia, para não dizer coisas "falsas" sobre o mundo dos cirurgiões. É todo um desejo de dizer coisas verdadeiras. Tudo isso contribui para essa ideia de que a literatura é também uma forma de conhecimento.

Mas, ao mesmo tempo, ela não se reduz a uma simples forma de conhecimento. Porque há o prazer estético: a alegria de ler as palavras escritas numa certa ordem, de uma certa maneira... Há todos os aspectos de composição, de estilo, etc. Evidentemente, é isso que distingue o escritor de um historiador ou de um sociólogo (mesmo quando eles escrevem bem).

Revista Plural Em A Cultura dos indivíduos ${ }^{7}$ você assume o paradigma da legitimidade cultural (Bourdieu, Passeron, Grignon), mesmo colocando nuances importantes. Você duvida do caráter monolítico do habitus e de sua simples transferência entre diferentes contextos de ação (o que constitui as "dissonâncias” ou variações inter e intraindividuais nas práticas culturais de alta e baixa

7 LAhIRE, Bernard. La culture des individus: dissonances et distinction de soi. Paris: Éd. La Découverte, 2004. (Collection Textes à l'appui/ Laboratoire des sciences sociales). Edição brasileira: A cultura dos indivíduos. Porto Alegre: Artmed, 2006. 
legitimidade) e nega também a correspondência automática entre "as práticas culturais de alta legitimidade" " "grupos dominantes" (e de maneira complementar, a correspondência entre "práticas culturais de baixa legitimidade" $e$ "grupos dominados"), contradizendo obras como A distinção. ${ }^{8}$ Contudo, você sustenta a existência de desigualdade simbólica entre as diferentes práticas culturais (por exemplo, a ópera é uma prática mais legítima do que o karaokê, o que pareceria evidente). Como podemos medir de maneira empírica e objetiva a desigualdade da legitimidade cultural entre as práticas sem recorrer a impressões ou consensos muito evidentes? Isso parece particularmente complexo para as práticas e os produtos culturais de legitimação recente ou instável, como o romance policial ou as histórias em quadrinhos.

Bernard Lahire Essa é uma questão extremamente difícil. Porque quando se tenta compreender, mesmo grosseiramente, a cultura legítima, muito legítima, medianamente legítima, muito pouco legítima, etc., você tem dois tipos de reação em um público. Você tem gente que diz: "por que para você a história em quadrinhos é um tipo de cultura menos legítima que Proust ou algum outro?" e dizem: "prove que Proust é superior à HQ". De outro lado, há pessoas que dizem: "mas é evidente isso que você diz, porque a HQ não é literatura". Então você tem gente que pode considerar que o que você diz no fundo é banal, e outros que de fato se opõem a isso e que ficam chocados. É muito difícil explicar que o sociólogo não está lá para dizer que as HQs não são tão boas, mas para constatar que efetivamente elas são julgadas como menos boas. A seguir, a questão extremamente difícil a ser tratada é: como saber o grau de legitimidade cultural de uma prática? N'A cultura dos indivíduos eu retomo um argumento de Marx que pode parecer tautológico, mas que é muito útil quando se pesquisa. Marx diz que "a ideologia dominante é a ideologia da classe dominante”. Se você toma essa fórmula e a aplica ao domínio da cultura - "a cultura dominante é a cultura da classe dominante" -, ela talvez seja tautológica, mas cruzando a classe social com as práticas culturais, você pode fazer uma ideia do que é consumido e praticado nas classes mais altas. Haverá sem dúvida colegas que dirão também "mas por que você considera essa classe como superior?". Mas aí eu abandono o combate, porque se alguém não considera que há hierarquias sociais, então não há mais sociologia... Mas se consideramos que há hierarquias sociais, que há os mais pobres, é difícil saber onde cortar, mas de fato é evidente que há pobres, há aqueles um pou-

8 Bourdieu, Pierre. La Distinction: Critique sociale du jugement. Paris: Minuit, 1982. (Collection Le sens commun). Edição brasileira: A distinção: crítica social do julgamento. São Paulo: EdUSP, 2007; Porto Alegre: Zouk, 2007. 
co menos pobres, há ricos e há muito ricos. Bom, se cruzarmos estatisticamente, mesmo com instrumentos que não são perfeitos (na França utilizam-se as categorias sócio-profissionais. Por exemplo, você pode ter o grupo dos operários e no seu interior há operários qualificados, operários pouco qualificados, etc. Você pode fazer os arranjos que quiser, depois) com as práticas, você vê que há preferências culturais que são muito marginais junto às classes superiores e você tem preferências culturais que são muito marginais junto às classes populares. Muito poucos operários se encontram em concertos de ópera. Muito poucos operários, praticamente nenhum operário sem grande capital escolar, se encontra em um teatro clássico, etc. Há alguma coisa de tautológico: como o mundo social é hierarquizado, é essa hierarquia que contribui para constituir os graus de legitimidade. No momento em que há alguém legítimo que começa a fazer alguma coisa, as pessoas consideram isso igualmente legítimo. Na corte do rei Luis XIV, se o rei fazia algo, as pessoas queriam imitar o rei. O sistema da moda é assim, também: há pessoas que dão "o bom gosto", que dizem "eis o bom estilo", "eis a boa vida", e há outros que tentam correr atrás desse estilo de vida, dessa maneira de viver, desse estilo de literatura que se lê, etc.

Então, bom, as primeiras coisas a serem feitas, em minha opinião, são os cruzamentos estatísticos, para ver quais são as práticas culturais da classe dominante. Depois, há o trabalho de historiador, que mostra como é construída a legitimidade de um objeto. Por exemplo, sobre a história em quadrinhos, há colegas que trabalham sobre o crescimento da legitimidade da história em quadrinhos. Isso se trabalha empiricamente, com o estudo das tomadas de posição, dos discursos. É interessante considerar, por exemplo, a partir de qual momento um grande editor muito legítimo começou a publicar histórias em quadrinhos. Ou: a partir de qual momento as pessoas altamente escolarizadas, cultivadas, etc., fazem a escolha de HQs, quando eles poderiam ser pintores, desenhistas, etc. Se pode ver isso! É a mesma coisa com o jazz! O jazz ascendeu à legitimidade porque se viu, cada vez mais, pessoas altamente formadas musicalmente que fizeram a escolha pelo jazz e que o fizeram progredir. E depois você tem os críticos musicais que defendem nas revistas (sobretudo "chiques") o jazz, a revolução do be-bop e coisas assim. E se viu como isso aumenta a legitimidade do jazz, ao ponto de que o jazz é hoje em dia altamente considerado na Europa. Nesse momento há concertos de jazz que podem ser considerados "mais chiques" que certos concertos clássicos. E devemos lembrar que nos anos 1930 o jazz foi considerado um gênero musical muito baixo, como "a 
música dos pretos", 9 com uma visão muito racista. Havia um acadêmico francês, George Duhamel, que disse que o jazz era "a música dos negros", ${ }^{10}$ um termo muito pejorativo na França. E, bom, esse tipo de música também era comentada como "música para dançar", "música ligeira”, enfim, "não a verdadeira música”. E nos anos 1960 já é uma música extremamente chique.

Então, isso quer dizer que se pode trabalhar sobre esse aumento de legitimidade, é preciso trabalhar as críticas, a formação dos autores, é necessário trabalhar os editores de música, a qualidade da sala que aceita a música de jazz, etc. E se pode fazer essa mesma reconstrução sobre as histórias em quadrinhos, sobre o romance policial, sobre o romance de ficção científica... E, assim, paulatinamente se chega a uma visão um pouco clara sobre uma situação que não é jamais definitivamente fixada. Hoje em dia as histórias em quadrinhos têm uma posição muito mais alta que há quarenta anos. Pode-se observar como anos atrás as histórias em quadrinhos foram excluídas da escola. Ela era uma subliteratura. Agora, se vê entrar nas bibliotecas das escolas primárias clássicos das histórias em quadrinhos, como Tintin (Hergé), Asterix e Obelix (Goscinny e Uderzo), etc. Quer dizer, de repente há "clássicos" nas HQs. E encontramos agora, nos manuais escolares, nos materiais sobre os gauleses, trechos de Asterix. Vimos também crescer a literatura para jovens, que entrou no corpus da literatura legítima ensinada no liceu.

Então, tudo isso são movimentos que devem ser estudados. É um trabalho muito longo e responde a certo caráter cético da sociologia, que crê que não haja coisas que se vejam assim, de forma fácil. É necessário multiplicar os índices para chegar a mostrar que pelas propriedades de seu público, pela recepção crítica, pelo lugar onde ele está publicado, pelo nome do editor, etc., há agora tal posição na hierarquia.

Lamento ter me alongado, mas é uma questão muito, muito complicada.

Revista Plural Há outra questão sobre o paradigma da legitimidade e o funcionamento das diferenças culturais como desigualdades sociais. Em obras clássicas desse paradigma, as práticas de "alta legitimidade" são associadas à cultura humanista e literária europeia, e as práticas de "baixa legitimidade" a uma combinação das culturas folclóricas tradicionais e das indústrias culturais ou cultura de massa. Contudo, em sociedades culturalmente heterogêneas como a brasileira, que integra em sua identidade nacional diferentes matrizes (afro-

9 "La musique des noirs" no original [Nota dos entrevistadores].

10 "La musique des nègres" no original [Nota dos entrevistadores]. 
-brasileira, ameríndia, imigração oriunda de diversos países), parece complicado classificar as diferentes práticas culturais em um cenário único de concorrência pela legitimidade. Talvez isso se produza recentemente nas sociedades europeias cada vez mais interculturais, o que põe em questão o caráter monolítico das identidades nacionais. Como podemos considerar em uma escala única de legitimidade práticas e esferas culturais tão diversas que parecem algumas vezes tão isoladas umas das outras?

Bernard Lahire $\mathrm{N}^{\prime}$ A cultura dos indivíduos eu considerei esse problema porque, justamente, penso que uma das faltas da teoria da legitimidade cultural, como foi formulada por Bourdieu, é de pensá-la a partir de uma escala única. Então, mesmo em um país como a França, isso é cada vez menos simples. E isso começou a ser menos simples com o desenvolvimento das indústrias culturais: a televisão, o rádio, a internet etc., que modificaram muito as relações de forças entre os tipos de culturas. Há a cultura do entretenimento de um lado, a "cultura acadêmica", "educada" etc., de outro. Mas, de fato, os intelectuais que aparecem na televisão não são respeitados, as pessoas riem deles. Podemos ver um intelectual na televisão e frequentemente há um humorista que dirá: "Ah, não! O que você disse é uma besteira". Há uma inversão do jogo nos anos 1980 que é muito interessante. Bourdieu, em 1982, com seu livro A economia das trocas linguísticas, ${ }^{11}$ apareceu em um programa de televisão sobre literatura. E ele estava sentado ao lado de um cantor popular que utiliza um linguajar com gírias, Pierre Perret. Bourdieu caiu em uma armadilha quando Pierre Perret disse: "Lamento, mas eu não sei se eu compreendi o que Bourdieu escreveu, eu tentei, mas não compreendi nada", coisas assim. E Bourdieu ficou incomodado. Penso que ele não compreendeu que não há um único mercado dominante. Eu falei muito dessa pluralidade de mercados n'A cultura dos indivíduos. Se há muitos mercados, a posição dominante em um mercado é pouco valorizada em outro. Bourdieu, como professor do Collège de France, é o representante da posição mais alta na cultura acadêmica e educada, mas nessa situação na televisão, pode parecer como um tipo incompreensível, arrogante, etc. Se estamos em uma sala de aula e alguém diz que não compreendeu os textos de Bourdieu, será dito a ele: "Então saia da minha aula, vá trabalhar para compreender", mas na televisão não se pode fazer isso. Não há um único mercado. E é um erro de Bourdieu dar a impressão de que há um único mercado, que as classes populares são sempre dominadas e que a única coisa que

11 Bourdieu, Pierre. Ce que parler veut dire: l'économie des échanges linguistiques. Paris: Fayard, 1982. Edição brasileira: A economia das trocas linguísticas: o que falar quer dizer. São Paulo: EdUSP, 1996. 
elas podem fazer é tentar imitar as outras classes. A ideia de vergonha cultural, em Bourdieu, é muito forte. A ideia de que nos meios populares há uma vergonha e que ninguém diz que se aborrece com a música clássica. Quando eu fiz minha pesquisa eu não encontrei essa vergonha: quando alguém não gosta de música clássica, diz: "eu não gosto de música clássica”, e quando eles adoram um cantor popular, eles dizem: "eu adoro esse cantor popular", de maneira totalmente assumida. Então, eu penso que Bourdieu exagerou muito. E falando da Europa - eu sei que o Brasil é especialmente complexo - mas, mesmo falando da Europa, eu penso que há muitos mercados e que eles estão em concorrência pela apropriação da atenção das pessoas.

É a questão do tempo! Podemos ver como é o tempo de consumo de televisão em relação ao tempo de leitura. E entre os jovens se pode ver como o tempo de leitura decresce em relação ao tempo de consumo de televisão. Isso quer dizer que a televisão consegue captar o tempo, a atenção e o interesse dos jovens de tal maneira que não há mais tempo para ler. É uma relação de força.

E encontramos no mundo social pessoas que não se situam na mesma escala de legitimidade. É necessário complexificar um pouco as coisas. Porque em todos esses mercados há graus de legitimidade. Por exemplo, eu tenho um filho de 16 anos, e nessa idade ele não se interessa pela música clássica. Mas ele e seus amigos são muito conhecedores no domínio da música eletrônica contemporânea, ou outros do heavy metal, etc. Nesses espaços você tem grupos "muito legítimos", muito pouco conhecidos, muito chiques para eles, etc. Quando eu escrevi A cultura dos indivíduos havia um jovem que respondia à pesquisadora: "sim, eu ouço heavy metal, mas são grupos que você não conhece, não pode conhecer, são grupos noruegueses, pouco conhecidos”. Trata-se de estratégias de distinção! Você pode encontrar pessoas que têm 60 anos que escutam Xenákis ${ }^{12}$ ou certas peças de Boulez, e eles dirão que a música eletrônica é simplesmente distração, diversão, etc. Mas não! Para os jovens, é um outro mercado.

Então é preciso considerar essa variedade. Mesmo entre os jovens, há uma grande variedade. Há gente que prefere cantoras como Christina Aguilera ou Britney Spears (na época de minha pesquisa, mas isso já deve ter mudado), mas há meninos que diziam: “ah, é uma porcaria! As meninas amam isso...”. São jogos de legitimidade. Com isso, eles querem classificar essa música como "estúpida", essa outra como “inteligente”, etc. São jogos de distinção que operam em mercados extremamente diferentes.

12 Yannis Xenákis, compositor de música eletrônica de origem grega e naturalizado francês [N. dos Es.]. 
Revista Plural No livro La condition littéraire ${ }^{13}$ você introduz o conceito de "jogo literário" (em oposição tanto ao de "campo literário", de Bourdieu, quanto ao de "mundo da arte", de Becker). Com esse conceito você descreve uma atividade intermediária entre o trabalho e o lazer que não pode garantir a independência econômica dos escritores e lhes impõe a necessidade de um "segundo ofício". Esse conceito parece definir de forma muito precisa as condições materiais e a realidade profissional da maior parte dos escritores (a pesquisar sobre a utilização do tempo, fontes de renda ou sobre a possibilidade de autonomia para seus projetos literários). Mesmo assim, você foi criticado por Gisèle Sapiro" por seu "objetivismo positivista", que compreende a escrita literária somente a partir de suas condições materiais de exercício. Segundo Sapiro, a analogia com o jogo teria limites nos planos subjetivo e objetivo:

No plano do vivido, a illusio é um efeito de campo irredutível a um jogo, pois ela implica geralmente em um dom de si, um investimento total dos agentes que subordinam suas atividades e projetos de vida à ambição literária. No plano objetivo, a illusio não é somente partilhada por agentes que participam do campo literário, mas adquiriu um reconhecimento social que faz com que não se possa assimilar essa atividade, mesmo exercida sem contrapartida financeira, a um lazer. O reconhecimento do escritor por seus pares lhe proporciona um capital simbólico, uma consideração que lhe confere uma verdadeira posição na sociedade (SAPIRO, 2007, p. 13).

Segundo suas pesquisas empíricas, essa illusio é tão forte entre os escritores e tão difundida socialmente quanto quer Sapiro? Isso justifica para todos os escritores a analogia de "vocação", de forte conotação religiosa, que ela propõe? Bernard Lahire Bom, há várias coisas; eu abordarei a crítica de Gisèle Sapiro para poder lhes explicar porque ela faz isso. Sapiro fez uma resenha nos Annales, uma revista de historiadores, ${ }^{15}$ enquanto em meu livro eu critico seu trabalho sobre os

13 Lahire, Bernard. La Condition littéraire: La double vie des écrivains, Paris: Éditions La Découverte; Laboratoire des Sciences Sociales, 2006.

14 SAPIRo, Gisèle. 'Je n'ai jamais appris à écrire'. Les conditions de formation de lavocation d'écrivain. Actes de la recherche en sciences sociales, Paris, $\mathrm{n}^{\mathrm{0}}$ 168, p. 12-33, 2007. Disponível em: http:// www.cairn.info/revue-actes-de-la-recherche-en-sciences-sociales-2007-3-page-12.htm. Acesso em: 26 de junho de 2017.

15 SAPIRo, Gisèle. Compte rendu de Bernard Lahire, La Condition littéraire. La double vie des écrivains (La Découverte, 2006). Annales, Paris, $\mathrm{n}^{\circ}$ 4, p. 947-949, 2007. Disponível em: https:// www.cairn.info/revue-annales-2007-4-page-921.htm>. Acesso em: 23 de maio de 2015. 
escritores durante "a resistência". ${ }^{16}$ Ora, ela não menciona o fato de que eu a tenha criticado. Evidentemente, essa crítica é o motivo real de sua resenha, extremamente dura e agressiva, o que é muito incômodo. Eu não tive o direito de resposta, que eu pedi à revista, porque ela diz coisas falsas sobre meu trabalho. E eu não tive a possibilidade de responder pessoalmente, porque ela não está na mesma instituição que eu. Eu não tive meu direito de resposta e ela continuou [a sustentar sua crítica] nesse artigo sobre a "vocação de escritor" na Actes de la Recherche en Sciences Sociales.

Bom, Gisèle Sapiro é uma bourdieusiana ortodoxa, aluna de Bourdieu, que no momento dessa resenha dirigia o Centre de Sociologie Europeènne fundado por Bourdieu, e que tenta dirigir a revista Actes de la Recherche en Sciences Sociales. Então ela se toma por Pierre Bourdieu. Seu problema é defender os conceitos de Bourdieu que, para ela, são intocáveis. Então sua acusação a meu trabalho é motivada por isso, porque definitivamente isso do que ela me acusa é muito confuso.

Se eu quisesse responder a todas suas críticas, isso demandaria muito tempo... Ela disse que eu sou positivista: eu fiz uma pesquisa. Se isso quer dizer ser positivista, bom, de acordo, eu sou positivista, não há problema, e eu espero que haja também muitos sociólogos positivistas em todo o mundo, porque isso seria formidável. Depois, ela me acusa de me interessar pelas condições materiais dos escritores. E eu não entendo porque não se teria o direito de estudar as condições de vida e de criação dos escritores.

De fato, essa lacuna tinha sido criticada por mim no livro La condition littéraire: pode-se reduzir a vida dos escritores à sua situação no campo literário? No trabalho de Sapiro ela tenta fazer isso. Considero que o comportamento da maior parte dos escritores no regime de Vichy estudados por ela não é compreensível se você não sabe que a maior parte dos poetas tem uma segunda profissão. Por definição, para um poeta é impossível viver do que se escreve. Então, a maior parte dos poetas tinha uma segunda profissão. Com o início do regime de Vichy e sua imposição de censura, eles tinham uma profissão e podiam parar sua atividade literária. Quanto aos romancistas, eles devem continuar escrevendo, porque frequentemente eles vivem da literatura. Eles tinham um interesse material. Bom, há coisas assim! E eu não consigo compreender que ela não queira ver que nem tudo se passa no interior do campo (literário).

Esse é o núcleo de minha crítica. Enfim, a noção de “jogo” não está contra a noção de "campo literário". Simplesmente ela diz que é necessário renomear o

16 SAPIRO, Gisèle. La guerre des écrivains, 1940-1953. Paris: Fayard, 1999. 
campo literário porque ele não é um campo como os outros. E o mais importante de sua diferença é que a maior parte das pessoas que está no interior do campo está também alhures. São escritores que são também médicos, que são advogados, que são professores, jornalistas, etc. A grande maioria dos escritores, na França, hoje em dia, possui uma segunda profissão, principalmente professor e jornalista. No livro La condition littéraire, eu digo que para compreender como funciona o "jogo literário" é necessário saber que ele não é como o campo sociológico, por exemplo, onde nós somos pagos pelo Estado ou pela Universidade para estar constantemente no universo dos sociólogos. Os escritores, não mesmo!

Então, é uma primeira constatação. É um meio que não tem a mesma estabilidade, porque os escritores não são pagos regularmente. A única tentativa disso aconteceu na União Soviética, e não durou muito tempo - pagar um salário aos escritores, regular, para que eles trabalhem com estabilidade. Eu não quero dizer que seja uma boa proposição, hein, eu não sou político. Mas é uma primeira constatação. Isso tem consequências sobre o ritmo de publicação. Por que Flaubert pode fazer o que faz? Porque ele era rentista. Ele tinha tempo porque ele podia viver de suas rendas, ele não tinha necessidade de publicar com frequência. A maior parte dos escritores que vive de sua escrita tem a necessidade de escrever mais rápido. $\mathrm{O}$ caso mais conhecido é Balzac, que escrevia para pagar suas dívidas. Hoje em dia os críticos podem observar como ele escrevia rapidamente, as incoerências nos textos, os esquecimentos... Mas, sim, ele escrevia rápido. Muitos escritores escrevem em condições de urgência, no século XIX era necessário fornecer à imprensa passagens dos folhetins a serem publicados. Então, isso tem consequências sobre a natureza do que se escreve, sobre o ritmo de publicação, etc.

E por fim, última coisa, é necessário levar em conta que uma parte das profissões que as pessoas têm no exterior [do campo literário], são profissões em que também se utiliza a escrita. E há ligações e efeitos sobre a escrita literária. Em minha pesquisa sobre Kafka observei que a escritura literária de Kafka possui conexões com sua formação de jurista, com a escritura jurídica. Ele escreve frequentemente como um jurista, desviando as maneiras jurídicas de escrever.

Tudo isso contribui para a compreensão da atividade literária, contrariamente ao que pensa Gisèle Sapiro, que decidiu parar de pensar após Pierre Bourdieu e reage com muita agressividade a toda a tentativa de avanço científico. Eu não sou o único. Isso ocorre com todas as pessoas que começam a deslocar um pouco as coisas, a propor questões que Bourdieu não propôs. Então, há pessoas como Gisèle Sapiro, com o ponto de vista ortodoxo, que vão chamar à ordem e dizer que isso não é permitido. 
Revista Plural É interessante que Bourdieu já explicou essa atitude...

Bernard Lahire Absolutamente interessante! É digno de nota... De fato, eu também tenho um lado provocador. O que os enerva mais é quando eu cito Bourdieu para falar de seus discípulos. Porque Bourdieu falou muito bem n'As Regras da Arte do devir dos discípulos. E eu penso, francamente, que Bourdieu pensava também em seus discípulos quando ele escreveu isso. Ele é suficientemente sutil para fazê-lo. No fim de sua vida, ele retomou contato com Jean-Claude Passeron e lhe disse: "eu tenho vontade de conversar com você, quero retomar o contato que foi interrompido vinte anos atrás". E disse também: "Você me conhece, eu posso conversar somente com você". Bom, isso é um testamento, hein? Infelizmente, ele não pôde discutir com seus discípulos. Eu penso que eles fazem muito mal à obra de Bourdieu, tentando defendê-la dessa forma. Como fizeram muito mal à sua obra os discípulos de Marx, os de Freud e de todos os grandes nomes que se tornaram objetos de culto...

Revista Plural Uma questão sobre consumo cultural. Em seu trabalho, você dá atenção à pluralidade de consumos culturais e à pluralidade de socializações que possibilitam esse consumo. Você pensa que essa possibilidade de transitar em diferentes mercados e consumir produtos muito diferentes (como, por exemplo, no Brasil, onde se consome ópera e música sertaneja, música regional...) é possível para todos os grupos sociais ou específica de certos grupos com uma certa socialização? Bernard Lahire Bom, eu posso falar sobre a França, que é o espaço que eu estudei. Porque é preciso fazer pesquisa para fazer afirmações. Eu encontrei isso, eu tentei analisá-lo. E para fazer o controle do que se fez é necessário às vezes recomeçar a pesquisa. Para falar do Brasil, seria necessário também fazer uma pesquisa assim aqui no Brasil. Então, para o caso da França, para os anos que eu estudei, eu mostrei que são as classes médias que desenvolvem primeiro as mais numerosas variações entre práticas e produtos de diversas legitimidades, depois as classes superiores e, enfim, as classes populares. Então, mesmo quando as variações são majoritárias em todas as classes sociais, elas são massivas para as classes médias, muito majoritárias para as classes superiores e um pouco menos majoritárias nas classes populares. Há uma explicação lógica, ao menos para o caso da França, que explica por que é mais fácil para as pessoas que possuem uma certa cultura, uma certa educação cultural, descer aos produtos "mais fáceis", que demandam "menos formação", "menos cultura, leitura", etc., que fazer o inverso. Então, compreende-se que haja menos pessoas de classes populares que "ascendem", mesmo de tempos em tempos, a diferentes práticas culturais (musical; literária; visitas cul- 
turais, como a museus, etc.) muito legítimas porque há barreiras que são muito fortes. Ao mesmo tempo se viu um enfraquecimento das prevenções contra as culturas populares. Vê-se que os jovens misturam coisas diferentes: eles podem ter uma alta concepção e apreciação da literatura e depois eles assistem na televisão a um espetáculo muito popular, dizendo nas entrevistas: "sim, eu sei que isso não presta, eu sei que é ruim, mas me relaxa". Veem-se frequentemente atitudes como essa. Além disso, é mais frequente nas classes médias e superiores a ideia de que "eu tenho direito de me distrair... Eu gasto meu tempo com a cultura popular porque estou muito seguro da legitimidade da minha cultura”. Observam-se também nas classes populares acessos imprevistos às culturas legítimas, como por meio da televisão. Na França há canais educativos, culturais, que propõem documentários, filmes clássicos, etc., e se percebe que certas pessoas de classes populares têm acesso, por essa via, a produtos de alta legitimidade, que não se pode dizer que a televisão mostre ordinariamente. Então se pode dizer que é mais frequente nas classes médias e nas classes superiores.

Revista Plural Como se manifesta a "luta de si contra si"? Seria como a "hipercorreção" de classe média?

Bernard Lahire São pessoas que portam práticas diferentes, muito opostas e que estão em conflito. Mas não se trata de um relativismo cultural. Não é uma situação simétrica, de alguém que gosta ao mesmo tempo da cultura popular e da cultura clássica e que pensa que tudo tem o mesmo valor. Pode-se imaginar uma pessoa que gosta de um cantor popular, de um grupo pop ou de rock e que gosta também de música clássica, ópera, etc. Alguns deduzirão disso que nós estamos em uma sociedade pós-moderna onde tudo é igual e que não há mais alta cultura, etc. Bom, não é o que eu mostro em minha pesquisa. Nas entrevistas as pessoas dizem: "Eu gosto disso, eu gosto disso também, mas, enfim, eu sei que isso é mais importante que isso outro". Eu comecei a falar de "luta de si contra si" porque os entrevistados tentavam lutar contra a parte mais ilegítima de suas práticas.

\section{Revista Plural Como uma espécie de incômodo?}

Bernard Lahire Sim, eles comparam com o cigarro. É uma situação comparável ao fumo. Você tem um vício, uma disposição muito forte. E você fuma, mas ao mesmo tempo você se diz: "não é bom fazer isso". E o discurso é o mesmo com as práticas culturais: "eu chego à noite, estou cansado, eu vejo televisão, eu vejo qualquer besteira, estupidez, enfim”. E a linguagem é assim, eles utilizam termos pejorativos para suas próprias práticas. Há uma gíria francesa que diz: "eu fico comatoso 
diante da televisão", entrar em estado de coma. Todas essas expressões mostram que, para eles, a televisão é verdadeiramente o "baixo", alguma coisa não inteligente, estúpida, etc. E que, ao contrário, quando eles leem, quando eles escutam certas músicas, é mesmo mais importante. É alguma coisa que eles consideram menos embrutecedor, que isso os educa. Há várias expressões como essas que mostram que há o alto e o baixo. Por exemplo, “elevar-se” é uma expressão muito frequente, muito empregada com relação à música clássica, etc. Bom, é a hierarquia. Segundo essa percepção, com o rap você desce e com a música clássica você se eleva.

Então eles continuam a diferenciar... E me dizem nas entrevistas: "eu tento parar com a televisão, porque desde que eu comecei a ver televisão, eu leio menos". Eles estão em uma luta de si contra si, entre a parte legítima e a ilegítima. E é isso que é interessante hoje em dia, mas talvez desapareça um dia. Talvez um dia haja igualdade entre todas essas práticas porque, ao final das contas, é uma questão de relação de forças. Se as práticas ditas "de entretenimento" chegam a subir a um alto nível de legitimidade, as pessoas não pensarão mais nisso. As classes superiores interrogadas por Bourdieu nos anos 1960-70 não teriam jamais dito algo assim. Percebe-se que as classes superiores se habituaram a práticas em relação às quais mantinham uma boa distância aristocrática na época. Hoje em dia eles continuam a diferenciar, mas praticando também essas coisas, mesmo se com um pouco de vergonha. Eles dizem: "eu gostaria de parar". Como com o cigarro.

\section{Revista Plural Obrigado!}

\section{BIBLIOGRAFIA CONSULTADA}

Alves, Ana Rodrigues Cavalcanti. Dos habitus de classe aos patrimônios individuais de disposições: reflexões sobre a prática em Pierre Bourdieu e Bernard Lahire. Sociologias, Porto Alegre, ano 18, n 42, p. 294-327, 2016.

NogueIra, Cláudio Marques Martins. "Bernard Lahire: contribuições e limites de uma sociologia em escala individual”. In: VANDEnberghe, Frédéric \&, Véran Jean-François (orgs.). Além do habitus. Teoria social pós-bourdieusiana. Rio de Janeiro: 7Letras, 2016, p. 49-69.

Rosenfield, Cinara L. et al. Entrevista: Bernard Lahire. Sociologias, Porto Alegre, ano 17, $\mathrm{n}^{\mathrm{o}} 38$, p. 280-302, 2015.

VAndenberghe, Frédéric. "A sociologia na escala individual: Margaret Archer e Bernard Lahire”. In: VANDENBERghe, Frédéric \& Véran, Jean-François (orgs.). Além do habitus. Teoria social pós-bourdieusiana. Rio de Janeiro: 7Letras, 2016, p. 95-126. 
"Os pós-bourdieusianos: retrato de uma família disfuncional". In: VANDENBERGHe, Frédéric \& VéRAN, Jean-François (orgs.). Além do habitus. Teoria social pós-bourdieusiana. Rio de Janeiro: 7Letras, 2016, p. 27-36.

\section{BERNARD LAHIRE: UMA BIBLIOGRAFIA EM PORTUGUÊS}

LAHIRE, Bernard. A fabricação social dos indivíduos: quadros, modalidades, tempos e efeitos de socialização. Educação \& Pesquisa, São Paulo, no 41 (especial), p.13931404, 2015.

A transmissão cultural da ordem desigual das coisas. Pátio, Porto Alegre, p. 6-9, 2011.

A transmissão familiar da ordem desigual das coisas. Sociologia, Porto, $\mathrm{n}^{\mathrm{o}}$ 21, p. 13-22, 2011.

. Crenças coletivas e desigualdades culturais. Educação \& Sociedade, Campinas, $\mathrm{n}^{\circ}$ 84, p. 983-995, 2003.

. Diferenças ou desigualdades: que condições socio-históricas para a produção de capital cultural?. Fórum Sociológico, Lisboa, no 18, p. 79-85, 2008.

Elias, Freud e a Ciência do Homem. Revista Pensata, Guarulhos, v. 2, nº 1 , p. 202-212, 2012.

Esboço do programa científico de uma sociologia psicológica. Educação e Pesquisa, São Paulo, vol. 34, nº 2, p. 373-389, 2008.

Esplendores e misérias de uma metáfora: a construção social da realidade. Estudos de Sociologia, Recife, v. 1, nº 16, p. 13-32, 2010.

Indivíduo e mistura de gêneros: dissonâncias culturais e distinção de si.

Dados: Revista de Ciências Sociais, Rio de Janeiro, vol. 5o, nº 4, p. 795-825, 2007.

Indivíduo e misturas de gêneros: dissonâncias culturais e distinção de si. Sociologia: problemas e práticas, Lisboa, $\mathrm{n}^{0}$ 56, p. 11-36, 2008.

. “O campo, o mundo e o jogo: o universo literário em questão". In: JunQueIRA, Lília Maria (org.) Cultura e classes sociais na perspectiva disposicionalista. Recife: Editora Universitária UFPE, 2010, p.103-115.

O jogo literário e a condição de escritor em regime de mercado. Fórum Sociológico, Lisboa, $\mathrm{n}^{0}$ 19, p. 73-79, 2009.

Patrimónios individuais de disposições: para uma sociologia à escala individual. Sociologia: problemas e práticas, Lisboa, nº 49, p. 11-42, 2005.

. "Por uma Sociologia disposicionalista e contextualista da ação". In: JunqueIRA, Lília Maria (Org.) Cultura e classes sociais na perspectiva disposicionalista. Recife: Editora Universitária UFPE, 2010, p. 17-36. 
. Reprodução ou prolongamentos críticos?. Educação \& Sociedade, Campinas, $\mathrm{n}^{\mathrm{o}}$ 78, p. 37-55, 2002.

. Três observações sobre as famílias populares e a escola. Pátio, Porto Alegre, p. 36-37, 2013.

. Viver e interpretar o mundo social: para que serve o ensino da Sociologia?. Dados: Revista de Ciências Sociais, Rio de Janeiro, v. 45, nº 1, p. 45-61, 2014.

Homem plural : os determinantes da ação. Petrópolis: Vozes, 2002.

. Sucesso Escolar nos Meios Populares. As Razões do Improvável. São Paulo: Ática, 1997.

. A cultura dos indivíduos. Porto Alegre: Artmed, 2006.

Retratos sociológicos: disposições e variações individuais. Porto Alegre: Artmed, 2004.

. O singular plural. Cadernos do Sociofilo. Quarto Caderno, Rio de Janeiro, IESP-UERJ, p. 16-26, 2013.

Discurso proferido durante a cerimônia oficial de entrega da Médaille d'Argent do CNRS. Cadernos do Sociofilo. Quarto Caderno, Rio de Janeiro, IESPUERJ, p. 267-273, 2014.

"O homem plural ou a sociologia em escala individual". In: VANDENBERGHe, Frédéric \& Véran, Jean-François (orgs.). Além do habitus. Teoria social pós-bourdieusiana. Rio de Janeiro: 7Letras, 2016, p. 39-47.

Visser, Ricardo \& Junqueira, Lília (orgs.). Dossiê Bernard Lahire. Belo Horizonte: Ed. UFMG, 2017.

\section{ENTREVISTAS}

Entrevista com Bernard Lahire. ÁSKESIS, São Carlos, v.1, nº 1, p. 201-211, 2012.

Entrevista com o prof. Bernard Lahire.OLH@RES, São Paulo, v. 1, nº 2, p. 120-128, 2013. AmÂndio, Sofia. Entrevista com Bernard Lahire - Do Homem Plural ao Mundo Plural. Análise Social, Lisboa, v. XLVII(1 $\left.{ }^{\circ}\right), \mathrm{n}^{0}$ 202, p. 194-208, 2012.

Monteiro, Guilherme S.; Ferreira, Mariana T. Entrevista com Bernard Lahire. Plural, v. 19, $\mathrm{n}^{0} 2$, p. 153-163, 2012.

Rosenfield, Cinara L. et al. Entrevista: Bernard Lahire. Sociologias, Porto Alegre, ano 17, $\mathrm{n}^{\mathrm{o}} 38$, p. 280-302, 2015.

Scaramboni, Bruna A.; Suficier, Darbi M. Entrevista com Bernard Lahire. Revista Pensata, Guarulhos, v. 2, $\mathrm{n}^{0}$ 1, p. 213-227, 2012.

Wozniak, Philippe. Entrevista com Bernard Lahire. Cronos, Natal, vol. $10 \mathrm{n}^{0}$ 2, p. 165-177, 2009. 